\title{
Letters are functional in word identification
}

\author{
DOMINIC W. MASSARO and DAVID KLITZKE \\ University of Wisconsin, Madison, Wisconsin 59706
}

\begin{abstract}
Are words identified as if they are single-unit patterns, or does letter processing mediate word identification? In the main, accuracy experiments have been found to support the mediated model, whereas recent reaction time experiments have been interpreted in favor of the single-unit pattern hypothesis. In the latter experiments, subjects could search for a target word in a test word as quickly as for a target letter in a test letter. The analysis of these results, however, did not consider the role of parallel processing of individual letters, lateral masking, limited capacity, and similarity between the target and test alternatives. In the present experiment, the advantage of parallel processing of letters in words was attenuated by manipulating similarity. The reaction times showed a processing advantage for single letters over words. This result as well as all of the previous results can be described in terms of processing mechanisms of the mediated model, the same mechanisms that have already been utilized to describe the accuracy of letter and word identification in tachistoscopic experiments.
\end{abstract}

The understanding of visual processing in reading printed material has been a persistent goal of experimental psychology since its commencement. Given the current debate on basic issues in the identification of letters and words, it is evident that our current understanding may not be much greater than that available almost 100 years ago. This paper addresses itself to a persistent issue in reading: Are words identified via processing the letters that comprise them or are words processed as wholes, without analysis of their component letters? In a recent review of reading-related research, the results were interpreted as consistent with a model that assumes that processing of letters mediates word recognition (Massaro, 1975b). The critical assumptions of the model are that: (1) Letters are recognized on the basis of visual featural information; (2) a string of letters can be processed in parallel; and, (3) less visual information needs to be processed when letters spell a word, because the constraints of English orthography aid the reader in recognizing what might be present. The results of a number of letter and word accuracy experiments were described in terms of the model (Massaro, 1975b). The goal of the present paper is to amplify the application of the model in order to describe a series of recent experiments that measure the time it takes to recognize letters, words, and letters in words. Analysis of the reaction time experiments leads to a new experimental test between the mediated and whole-word models.

In a recent series of experiments by Johnson (1975), subjects were given a target item and then were required

This research was supported in part by NIMH Grant MH 19399 and a grant from the Wisconsin Alumni Research Foundation. John Theios provided helpful comments on an earlier version of the manuscript. Requests for reprints should be sent to Dominic W. Massaro, Department of Psychology, University of Wisconsin, Madison, Wisconsin 53706. to report whether a following test item was or was not the same as the target. In one experiment, subjects were given a target followed by 25 test items presented one at a time; in a second experiment, a new target item was presented before each test item. One variable of interest was whether the target and test items were single letters or whole words. In both experiments, the response latencies did not differ in the letter and word conditions. (Error rates were not reported for the individual conditions, but overall error rate was kept below 5\%.) This result and a second result to be discussed later in the present paper led Johnson to conclude that words, like letters, are processed as single-unit patterns and, therefore, no processing time differences between single letters and whole words would be expected.

The major limitation in an experiment such as Johnson's is that single letters and word strings differ along a number of more basic dimensions than the word-letter distinction. The most obvious difference is that a word contains a number of component letters; therefore, the more correct distinction may be single letters vs multiletter strings, regardless of whether they spell a word (Henderson, 1975). Other more subtle differences are made apparent when the processing task is considered. Five-letter strings allow the subject to process up to five letters in parallel, whereas no more than the single letter can be processed on single-letter trials. If the letters can be processed in parallel, the subject might benefit from the dissimilarity between test letters and target letters to a greater degree on the "different" trials in the word condition than in the single-letter condition. No constraints were made in the selection of the word strings, producing strings that were extremely different from one another. For example, "plot," "some," "manual," and "tropic" are words used in four- and six-letter word conditions. On "different" trials, each letter in the test word 
usually differed from its corresponding letter in the same spatial position in the target word. Accordingly, it might be argued that the population of words of a given length are more dissimilar from one another than are the set of single letters. If this were the case, a subject could perform with a less stringent criterion for deciding that a test item is the same as the target item in the word than in the letter condition.

If it is assumed that (1) a sequence of letters can be processed in parallel, (2) features of individual letters are extracted continuously, and (3) comparisons between extracted features and those in the target can occur before perception is complete, then a relatively parsimonious description of the results can be given. Shortly after the display is presented, when the subject has extracted a single feature in the single-letter condition, this feature can be checked against the features in the target letter. If the feature is different from those in the target letter, the subject would be able to select and execute a "no" response. If the feature matches a feature in the target letter, it would probably be premature to select a "yes" response, since that feature could be contained in a number of other letters besides the target letter. Accordingly, further processing of other features would be required before a response could be made. Now consider the target-word condition when the subject has extracted a single feature from each of the six letters in the word. At most, a different test word might share one or two letters in the same spatial positions as the letters in the target word. Accordingly, there should be enough discriminability information with just one feature per letter to allow the subject to select a negative response. When the test word is identical to the target word, the single features from each of the six letters should agree with those in the target word. Given that it would be highly unlikely that this correspondence would occur on "different" trials, it is safe for the subject to select a positive response after just a single feature from each of the letters is extracted and compared to those in the target word. Extraction and comparison processes that operate on a number of letters in parallel should produce an advantage for multiletter strings over single letters. Therefore, Johnson's (1975) finding that word targets were responded to as quickly as letter targets may indicate nothing about the uniqueness of word patterns except the fact that words have more letters than do single letters.

If the parallel processing model predicts an advantage of multiletter strings over single letters, why did Johnson find no difference? The reason is that, although words had the advantage of a larger number of letters, they also had a number of disadvantages. First, the letters in the words were naturally reduced in the perceived figure-ground contrast (discriminability), since they extended horizontally left and right of the fixation point, whereas the single letters were always presented at the point of fixation. Second, the perceived quality of the letters in the word string suffered because of lateral masking, the mutual degrading of adjacent letters in the display (Bouma, 1970, 1973; Estes, Allmeyer, \& Reder, 1976). The tradeoff between the advantage of parallel processing and the disadvantage of reduction of figure-ground contrast with increases in the number of letters makes possible any result, since the exact contribution of each is not known. Furthermore, if the parallel processing of the letters were limited in capacity so that the advantage first increased and then decreased with increases in the number of letters, then almost any result would be possible. Accordingly, Johnson's (1975) failure to find a difference between single letters, four-letter words, and six-letter words does not uniquely support the idea that words are processed as unitary patterns without reference to their component letters. The analysis reveals, instead, that it is incumbent on the investigator to account for all of the differences and lack of differences that are produced between the conditions resulting from manipulation of an independent variable. To summarize, Johnson's division of letter strings into single letters and words confounded a number of other important variables so that the results are not unambiguous.

The goal of the present experiment is to neutralize the advantage of parallel processing in words in order to make apparent the disadvantage of reduced figureground contrast in the word condition. The experiment should, therefore, produce faster reaction times for searching for letter targets than for searching for word targets. A subject processing multiletter strings can set the criterion for a yes or no decision so that fewer features per letter are required than the number of required features in processing single letters. This advantage, however, is dependent on the similarity between the target and test items in the target-search task. It is well known that increasing the similarity between the alternative stimuli increases the choice reaction time (Woodworth, 1938, p. 333). For example, Cattell (1902) showed that the time to say which of two gray surfaces was brighter was inversely related to the physical differences between the surfaces. Reaction times to letter strings increase with increases in the number of letters that are shared between the target and the test foil (Chambers \& Forster, 1975). Earlier, the present paper described how a subject could select a positive response if a single feature from each of the letters in the word matched one of the features in each of the corresponding letters in the test word. If a test foil shared all letters but one with the target word, however, a positive response at this stage would be premature. Accordingly, increasing the number of shared letters between a word target and a test foil should increase reaction times on word trials, since additional features have to be processed before a decision can be 
made. Johnson (1975) made no attempt to control for the similarity of the test foils to the target items, producing test foils that were naturally more dissimilar on word than on letter trials. The present authors predicted that increasing the similarity between the target and test foils should decrease the advantage of parallel processing on word trials and, therefore, produce a letter advantage, because of reduced figureground contrast and limited-capacity effects in processing word strings.

The current experiment investigated the role of similarity in the identification of words and letters. As in Johnson's letter-vs-word study (Experiment 3), half of the stimuli were nontargets and half were targets. However, unlike Johnson's study, half of the nontargets were similar to the target and half were dissimilar. On letter trials, similarity was defined in terms of whether two lowercase letters shared overall letter shape. Two letters were categorized as being the same type if they were both ascenders, descenders, or short letters (cf. Bouma, 1971). For example, given the target letter $h$, the letters $b, d, k$, and $f$ would be similar nontargets, whereas the letters $\mathrm{g}, \dot{q}, \mathrm{v}$, and $\mathrm{w}$ would be dissimilar nontargets. Similar word nontargets were words having three identical letters in the same position as the target. Dissimilar words were words having a letter of a different type at the same letter position at each of the four letter positions. For example, given the target word "mute," the similar nontargets were "mate," "mete," "lute," and "mule," whereas the dissimilar nontargets were "glad," "they," "plop," and "clod."

\section{METHOD}

\section{Subjects}

Twelve right-handed subjects were paid $\$ 4$ for participating in the experiment, which lasted $1 \mathrm{~h}$ for each of 2 days.

\section{Apparatus and Stimuli}

All stimulus events were controlled by a PDP-8/L computer. Two subjects were tested simultaneously in separate soundattenuated and darkened rooms. Each subject sat facing an oscilloscope (Tektronix Model 604), which was resting on a table. The table also held two response buttons labeled "TARGET" and "NONTARGET."

The alphabet consisted of lowercase sans-serif letters very closely resembling the typeface UNIVERS 55 . The letters were made by combining the basic strokes of points, straight horizontal, vertical, and diagonal lines, and quarter and half circles. The ratio of the overall height of ascenders and descenders to small letters was 3 to 2 , as was the ratio of the height of a small letter to its most usual width. The horizontal space between letters was one quarter the height of a small letter. Four-letter words subtended about $1.5 \mathrm{deg}$ of visual angle horizontally, and the distance between the tops of ascenders and the bottoms of descenders was about $1 \mathrm{deg}$ of visual angle. The CRT spot size (i.e., the size of one dot on the screen of the oscilloscope) was greater than the distance between any two contiguous dots. The positioning of dots in a stroke was done using the following algorithm. First, the end points of a stroke were plotted separately from the other points to insure that the junction of two strokes was painted only once. Since the length of the stroke was known, it was possible to compute to the nearest whole number the number of dots in that stroke. This number was then divided into the length of the stroke, to give the distance between each dot in the stroke. The dots of each letter were positioned as accurately as possible in a 144 by 96 matrix. Letters took about $1 \mathrm{msec}$ each to paint, but software routines enabled the experimenter to paint all of the letters in a test word in exactly the same time as required for a test letter. Therefore, a letter in the single-letter condition was not painted more of ten than a letter in the word condition. All strokes were painted at random. For example, if the word "dove" were being displayed, the first stroke painted might be the horizontal straight line in the letter $e$, followed by the painting of the lower semicircle in the letter $o$, and so on, until all of the points in the word were painted once. Each test item was painted in this way throughout the 300-msec presentation. In the single-letter case, the painting routine would simulate the painting of three additional letters, so that the time taken to paint a letter would be exactly the same for the letter and word items. Both letter and word displays were refreshed once every $4 \mathrm{msec}$.

\section{Procedure}

At the beginning of every trial block of 16 trials, a message stating "Target is " appeared on the screen for $4 \mathrm{sec}$, informing the subject of the identity of the target. The three words were presented vertically, followed by a faint dot for a fixation point. Two seconds later, the first test stimulus was presented, centered around the fixation point. All test stimuli were displayed for $300 \mathrm{msec}$, followed by the fixation point. Subjects had $2.3 \mathrm{sec}$ in which to make a response, before the onset of the next test trial. Each block of 16 test trials contained eight targets, four similar nontargets, and four dissimilar nontargets. For the word trials, a similar foil was a word having three of the same letters in the same letter position as the target. A dissimilar foil was a word that had a different letter than the target at each letter position. Letters were of three types, short letters $(a, c, e, m, n, o, r, s, u, v, w, x, z)$, ascenders $(b, d, f$, $h, i, k, l, t)$, and descenders $(g, j, p, q, y)$. For the single-letter condition, a similar foil was usually a letter of the same type and a dissimilar foil was usually a letter of a different type. The letter and word targets and nontargets are presented in the Appendix. Half of the subjects pressed the right-hand button to indicate the stimulus was a target, while the other half pressed the left-hand button.

Subjects participated in two 25 -min sessions, with a 5 -min break between sessions on each of 2 consecutive days. Each session consisted of a total of 10 letter and 10 word blocks, giving a total of 320 trials. The second session on each day replicated the first, except that different letter and word targets were used. The same lists were used on Day 1 and Day 2. In all sessions, the order of the targets within a session and the type of test items within a block were completely randomized. Subjects were informed of the nature of the task and were instructed to make as fast and as accurate responses as possible.

\section{RESULTS}

The data were first reduced to average correct reaction times at each treatment combination of days by sessions by word or letter target by type of test stimulus (target, similar nontarget, or dissimilar nontarget) for each subject. Since subjects averaged $2.6 \%$ errors over all conditions, there were slightly less than 80 trials per subject per data point for target conditions and 40 trials per subject per data point for each of the two nontarget conditions. 
Table 1

Mean Reaction Times (in Milliseconds) of Correct Responses as a Function of the Type of Test Display and Whether the Targets Were Letters or Words

\begin{tabular}{lccc} 
& \multicolumn{3}{c}{ Targets } \\
\cline { 2 - 4 } Type of Test Display & Letters & Words & Mean \\
\hline Targets & 460 & 495 & 477 \\
Dissimilar Nontargets & 515 & 542 & 529 \\
Similar Nontargets & 535 & 602 & 569 \\
Mean & 503 & 546 & \\
\hline
\end{tabular}

Overall reaction times were fastest for targets $(477 \mathrm{msec})$ and slowest for similar nontargets $(569 \mathrm{msec})$, with intermediate performance for dissimilar nontargets $(529 \mathrm{msec}) \quad[\mathrm{F}(2,11)=59.8$, $\mathrm{p}<.001]$. The manipulation of similarity was effective, in that responses to similar nontargets required $40 \mathrm{msec}$ longer than did responses to dissimilar nontargets. Reaction times were $43 \mathrm{msec}$ faster for letter stimuli than for word stimuli $[F(1,11)=348, p<.001]$. Table 1 shows that the size of the letter advantage varied as a function of the test stimulus $[F(2,22)=35$, $\mathrm{p}<.0011$. The letter advantage was 35,27 , and $67 \mathrm{msec}$ for targets, dissimilar nontargets, and similar nontargets, respectively. The letter advantage was significant even when the analysis was restricted to target and dissimilar nontarget trials $[F(1,11)=14.5, p<.005]$. Subjects were approximately $50 \mathrm{msec}$ faster on Day 2 than on Day $1[F(1,11)=7.30, p<.0025]$, but this variable did not interact with any of the other variables.

Table 2 shows that the error rates averaged between $1.5 \%$ and $3 \%$, except in the similar nontarget word condition, which gave an error rate of over $5 \%$. Accordingly, subjects were much more likely to make a false alarm on a nontarget word trial when the stimulus shared three letters with the target word. This result supports the idea that subjects can select and execute a response before processing of the test stimulus is complete. An early "yes" decision based on the large number of feature matches from the three matching letters would have produced a greater proportion of errors on the similar nontarget words.

\section{DISCUSSION}

The present experiment was successful in producing a letter advantage over words in the target-search task. The advantage of letters over words occurred even when the analyses were limited to only the target and dissimilar nontarget trials. By including similar nontarget trials, subjects could not maintain a very lax criterion of sameness because a nontarget test item could be very similar to the target word. Accordingly, subjects could not select and execute a positive response as quickly as they might have with a more lax criterion of sameness. Subjects were able to reject dissimilar nontargets more quickly than similar nontargets, however, suggesting that perceptual processing and comparison are continuous and overlapping processes, rather than discrete and successive stages. That is to say, subjects do not first perceive the test item and then compare it to the target item in memory; rather, they are able to make comparisons as partial information about the test item is resolved.

The analysis of Johnson's (1975) experiment and the present expanded replication weaken the conclusions Johnson reached in his paper. In another condition of Johnson's study, subjects were given a test word every $10 \mathrm{sec}$ and asked to classify each test word according to whether or not it contained a target item. In the word-target condition, the target word might be "block," and the subjects saw a list of five-letter test words and classified each test word in terms of whether it contained the target word. In the letter-target condition, the subject again saw a series of five-letter test words but responded whether or not each test word contained a particular target letter, for example, the letter $b$. The results showed an advantage of over $100 \mathrm{msec}$ for the target-word relative to the targetletter condition, which led Johnson to conclude that words are identified as unitary patterns, suppressing the identification of their component letters.

Johnson's conclusion that words are unique in that they are processed as single-unit patterns is also not justified by this result. First, identifying a part in a whole is a different task than identifying a whole in a whole. In general, it is probably more difficult to find a part in a whole (even when the location of the part is known) than it is to find a whole in a whole, regardless of how the whole is identified. Since the whole-part distinction is completely confounded with the word-letter distinction, it is not possible to determine whether Johnson's results are due to the way in which written language is processed or to the way in which wholes and parts of wholes are processed.

The results from this paradigm can also be explained by the same continuous parallel processing model described in the introduction. Rather than repeating that discussion here, however, the present section will simplify and formalize some of the assumptions of the model in order to facilitate the exposition of the manner in which it can describe the results. The critical component of the model is that words are

Table 2

Mean Percentage Errors as a Function of Type of Test Display and Whether the Targets Were Letters or Words

\begin{tabular}{lccc} 
& \multicolumn{3}{c}{ Targets } \\
\cline { 2 - 4 } Type of Target Display & Words & Letters & Mean \\
\hline Targets & 2.7 & 2.1 & 2.4 \\
Dissimilar Nontargets & 1.6 & 2.0 & 1.8 \\
Similar Nontargets & 5.3 & 2.2 & 3.8 \\
Mean & 3.2 & 2.1 & \\
\hline
\end{tabular}


processed in terms of their component letters and not on the basis of the supraletter features (cf. Massaro, 1975 b; Venezky \& Massaro, in press).

In the model, it is assumed that the resolution of the visual display occurs gradually, as revealed by backward masking and partial report experiments (Averbach \& Coriell, 1961; Massaro, 1975a, Sperling, 1960). For simplicity of exposition, however, the perception of the letters will be conceptualized as occuring in a twostage process. In the first stage, the overall shape or form of each letter is resolved. Bouma (1971) has referred to overall shape as the envelope which is defined as the outside form of the letter without regard to indentations. In this case, the lowercase letters $\mathrm{e}, \mathrm{o}$, and $c$ have small circular envelopes, the letters $n, m$, and $\mathrm{u}$ are rectangular, and so on.

It is assumed that the first stage of processing takes a fixed amount of time for each letter, designated $t_{e}$, for time to resolve the envelope. The second stage of processing follows the first and resolves the details of the envelope of the letter. This stage of processing takes time $t_{i}$, for time to identify the letter. In reading, the reader does not have to complete both stages of processing for each letter, but in many cases the letters can be unambiguously identified after the first stage of processing. For example, given the word "to," both letters can be identified on the basis of the first stage of processing. The resolution of the envelopes limits the alternatives for the first letter to $f, i, l$, or $t$, and to $\mathrm{c}$, e, and o for the second letter. Therefore, utilizing the rules of English orthography and meaning, the reader can identify the letter string as "to" since no other sequence of possible letters is a word in the English language. This simple model can account for the fact that words would be recognized better than single letters, since neither the letter $t$ nor the letter $o$ presented alone could be unambiguously identified until the completion of the second stage of processing. Therefore, the letters "to" would be identified in time $t_{e}$, whereas either letter alone would require $t_{e}+t_{i}$ for identification.

In letter- or word-target search tasks, it is assumed that the subject can select a response after envelope resolution or after the letters are identified, depending on the likelihood of a correct response at each of the stages. The subject maintains a fixed criterion to keep his false alarm rate at a low level. If the information available to the subject at the end of the initial enveloperesolution stage is sufficient to respond correctly with probability $P_{c}$, and $1-P_{c}<P_{f}$, where $P_{f}$ is the maximum false alarm rate set by the subject's criterion, then the subject outputs the response. Otherwise, he completes the second stage of processing and responds after it is complete. Of course, in the second case, the reaction time will be longer than in the first, in which a response was executed without the second stage of processing, saving time $t_{i}$.

The central purpose of the present paper is to show that this simple model can predict the findings that a test word can more readily be classified with respect to whether or not it is identical to a target word than with respect to whether or not the test word contains a particular target letter. The importance of the adequacy of the model is that it rests on the central assumptions that letters in words are perceived in the same way as are letters presented alone, and that word recognition is dependent on the resolution of the individual letters. Furthermore, the same visual features are used in word and letter recognition. Accordingly, it is not necessary to assume that words are recognized as single-unit patterns without reference to the letters which comprise them.

As in earlier developments (Massaro, 1975b), it was assumed that letters in a word are processed in parallel and that the subjects can perform a comparison after either the envelope-resolution or the letterresolution stage. The subject can be conceptualized as carrying out the task in the following manner. At the end of the first stage, the subject has resolved the envelopes of the test letters and compares each letter in the target word to the respective position of the test word (again in a parallel manner). If the target word contains at least a letters that contradict the respective envelopes of the test letters, the subject can respond "no." If at least b target letters agree with the respective envelopes of the test letters, the subject can execute a "yes" response. Otherwise, the subject must go on to Stage 2 processing before he makes a response. Criteria $a$ and $b$ would be set by the subject to keep errors within that prescribed by the experimental situation.

When subjects are asked to search for a target letter in a test word, however, each letter in the test word must be compared to the target letter. Although this can be done in parallel at the same rate as in the targetword condition, the subject will be less likely to execute a "yes" or "no" response at the end of Stage 1 if he wants to keep his error rate the same on target-letter and target-word trials. Why is this so? Consider the "yes" trials for the target letter "b" and target word "block" when the test word "block" is presented. At the end of Stage 1, it is assumed that the subject has resolved the envelope of each of the test letters. In the target-word condition, the subject would have a match on each of the five letter positions between the envelope and the appropriate letter of the target word. In the target-word case, the subject can be confident in a "yes" response at the end of Stage 1, since it is very unlikely that an incorrect test word would have letters whose envelopes exactly agree with all of the target letters. In the target-letter condition, the subject will also have a match at Position 1 and may also have matches at other positions, even though they do not contain the letter "b." However, it would be premature to respond "yes," since other letters besides "b" might be present at those positions. Accordingly, the Stage 2 process is required in the target-letter but not in the target-word condition.

The "no" trials will also produce differences between 
target-letter and target-word trials. Assume that the test word "heart" is presented and the subject resolves the envelope of each of the letters. In the target-word case, he should be confident in responding "no," since "heart" differs from "block" in envelope shape with respect to four target letters. In contrast, a "no" response when the subject is searching for $b$ would be premature, since $h$ and $b$ share the same envelope shape. This analysis shows that Johnson's (1975) results do not rule out models that assume that word recognition is based on the features of its component letters. In general, a letter in an incorrect test word will be more likely to differ in envelope shape from the letter in the corresponding spatial position in the target word than to have all the letters in the test word differ in envelope from the target letter. Accordingly, subjects can select a "no" response after envelope resolution more often in the target-word than in the target-letter condition.

Sloboda (1976) has carried out a series of experiments that are relevant to the present analysis. Sloboda (1976, Experiment 3) found that searching for a word target takes about 60 msec longer when all of the word foils differ from the target word by just one letter. Even so, searching for a target word was still faster than searching for a target letter in the test words. This result is not inconsistent with the present model, if it is assumed that the word targets still had the advantage along the similarity dimension. The present authors predict that, by including test words whose letters are completely dissimilar from the test letter, the ordering of the reaction times could be reversed. Searching for a target word in a set of test words with similar foils should take longer than searching for a target letter in a set of test words whose nontarget letters are completely dissimilar from the target letter.

Johnson (1975) also found that subjects could search for word targets $37 \mathrm{msec}$ faster than they searched for letter targets in the same word, even when the position of the letter target was known in advance. This result can be explained with the same mechanisms that account for searching for letter and word targets in letter and word test items. The present authors argued that the disadvantages of the reduced figure-ground contrast and limited capacity can offset the parallel processing advantage of searching for words in words relative to searching for letters in letters. Searching for a target letter in a specific position in a word, however, also has the disadvantages of reduced figureground contrast and limited capacity, but does not gain anything from parallel processing as in the wordtarget condition. Therefore, the advantage of word targets over searching for a letter target in a specific position in a word is to be expected from the letterprocessing model. The result does not uniquely support Johnson's idea that a word conceals the properties of its component letters and, therefore, must be recognized on the basis of supraletter features. Supporting this analysis, Sloboda (1976, Experiments 1 and 2) has shown that searching for a target letter is always slowed down by the presence of additional letters, regardless of whether or not the letter string spells a word. Subjects were asked to indicate whether a test letter was the same as a target letter or whether the left-most letter of a multiletter test string was the same as a target letter. Reaction times were $65 \mathrm{msec}$ longer when the test was a multiletter string for both the word and nonword strings. The same results occurred when the multiletter string was rearranged in a diamond configuration, as in " $\mathrm{W}_{\mathbf{R}}^{\mathrm{O}} \mathrm{D}$." Further evidence against supraletter features was provided by Groff (1975), who showed that only $20 \%$ of 283 high-frequency words in beginning reading books were represented by a unique shape.

Finally, Johnson (1975) calls attention to the inconsistency between his reaction time data and the letter-word studies carried out using accuracy measures in tachistoscopic displays (e.g., Reicher, 1969; Wheeler, 1970). The present authors' reinterpretation of his data, however, utilizes the same processing mechanisms that Massaro (1975b) used to describe the results of the accuracy experiments. The adequacy of these mechanisms to describe both types of studies makes apparent the converging operations (Garner, Hake, \& Eriksen, 1956) and therefore adds a somewhat predictive rather than simply descriptive interpretation of Johnson's results and those of the experiment reported here.

An implicit assumption that Johnson (1975) made in the design and interpretation of his experiments goes back to Wundt's justified criticism but incorrect solution to Donder's interpretation of his c-reaction time paradigm. Although the observer only responds to target trials, it cannot be assumed that response selection is not required and, therefore, that the c-reaction time eliminates the response-selection stage of the b-reaction. The observer chooses between one movement and another in b-reaction and between movement and no movement in the c-reaction. Wundt's solution was the d-reaction, in which the same response was to be made to every stimulus, but not until the stimulus was identified. In this case, the d-reaction would differ from the simple a-reaction by the insertion of discrimination only. Berger's (1886, cited in Woodworth, 1938) analysis, however, was that the d-reaction offers no check of whether identification actually took place before the response was initiated since the same response is made to all stimuli. The analogy that the present authors would like to draw between Wundt's error and Johnson's interpretation is that, like Wundt, Johnson (1975) assumed that the test stimulus was completely identified before a response was initiated.

As a final note, it seems important to acknowledge the related theoretical work of Estes (1975) and Townsend (1974). Estes assumes that subjects, faced with a letter string, can select a response on the basis of the processing output at the level of features, letters, or letter groups. Accordingly, his model allows response 
selection to take place as soon as a distinguishing feature or set of features is encountered. Townsend defined four types of mechanisms that must be accounted for in the processing task. The self-terminating vs exhaustive processing dichotomy is relevant to the analysis in the preceding paragraph. The independent vs dependent processing dimension is important in isolating the role of lateral masking and the utilization of orthographic regularity. And, of course, the serial vs parallel and the limited vs unlimited capacity processing distinctions are relevant to the idea that the advantage of parallel processing can be offset by a limited capacity. Townsend's work has made apparent the necessity of accounting for the contribution of each of the processing operations in a psychological task.

\section{REFERENCES}

Averbach, E., \& Coriell, A. S. Short-term memory in vision. Bell System Technical Journal, 1961, 40, 309-328.

Bouma, H. Interaction effects in parafoveal letter recognition. Nature, 1970, 226, 177-178.

Bouma, H. Visual recognition of isolated lowercase letters. Vision Research, 1971, 11, 459-474.

Bouma, H. Visual interference in the parafoveal recognition of initial and final letters of words. Vision Research, 1973, 13. $767-782$.

Cattell, J. M. The time of perception as a measure of differences in intensity. Philosophische Studien, 1902, 19, 63-68.

Chambers, S. M., \& Forster, K. I. Evidence for lexical access in a simultaneous matching task. Memory \& Cognition, 1975, 3, 549-559.

Estes, W. K. Memory, perception, and decision in letter identification. In R. L. Solso (Ed.), Information processing and cognition: The Loyola symposium. Hillsdale, N.J: Erlbaum, 1975.

Estes, W. K., Allmeyer, D. H., \& Reder, S. M. Serial position functions for letter identification at brief and extended exposure durations. Perception \& Psychophysics, 1976, 19, 1-15.
Garner, W. R., Hake, H. W.. \& Eriksen, C. W. Operationism and the concept of perception. Psychological Review, 1956, 63, 317-329.

GrofF, P. Research in brief: Shapes as cues to word recognition. Visible Language, 1975, 9, 67.71.

Henderson, L. Do words conceal their component letters? A critique of Johnson (1975) on the visual perception of words. Journal of Verbal Learning and Verbal Behavior. 1975. 14, 648-650.

Johnson, N. F. On the function of letters in word identification: Some data and a preliminary model. Journal of Verbal Learning and Verbal Behavior, 1975, 14, 17-29.

Massaro. D. W. Experimental psychology and information processing. Chicago: Rand-McNally, 1975. (a)

Massaro, D. W. Primary and secondary recognition in reading. In D. W. Massaro (Ed.), Understanding language: An information processing analysis of speech perception. reading, and psycholinguistics. New York: Academic Press, 1975. (b)

Reicher, G. M. Perceptual recognition as a function of meaningfulness of stimulus material. Journal of Experimental Psychology, 1969, 81, 275-280.

Sloboda, J. A. Decision times for word and letter search: A holistic word identification model examined. Journal of Verbal Learning and Verbal Behavior, 1976. 15, 93-101.

Sperling, G. The information available in brief visual presentations. Psychological Monographs, 1960, 74(11, Whole No. 498).

TownSEND, J. T. Issues and models concerning the processing of a finite number of inputs. In B. H. Kantowitz (Ed.), Human information processing: Tutorials in performance and cognition. Hillsdale, N.J: Erlbaum, 1974.

VENEZKY, R. L., \& MASSARO, D. W. The role of orthographic regularity in word recognition. In L. Resnick \& P. Weaver (Eds.), Theory and practice of early reading. Hillsdale, N.J: Erlbaum, in press.

WheEler, D. D. Processes in word recognition. Cognitive Psychology, 1970, 1, 59-85.

Woodworth, R. S. Experimental psychology. New York: Holt, 1938.

(Received for publication January 21, 1977.)

Appendix

Word and Letter Stimuli Used in the Experiment

\begin{tabular}{|c|c|c|c|c|c|}
\hline Target & Similar Nontarget & Dissimilar Nontarget & Target & $\begin{array}{c}\text { Similar } \\
\text { Nontarget }\end{array}$ & $\begin{array}{l}\text { Dissimilar } \\
\text { Nontarget }\end{array}$ \\
\hline dell & doll, bell, dill, cell & clam, agog, chop, stem & e & $c, o, a, s$ & $\mathrm{~m}, \mathrm{j}, \mathrm{l}, \mathrm{f}$ \\
\hline felt & melt, feet, fent, belt & clan, alms, slog, span & g & $q, p, y, j$ & $\mathbf{b}, \mathbf{h}, \mathbf{i}, \mathbf{k}$ \\
\hline rife & life, rift, rice, wife & pact, duct, goad, drub & $\mathrm{t}$ & $\mathrm{f}, \mathrm{i}, \mathrm{l}, \mathrm{h}$ & $\mathrm{g}, \mathrm{p}, \mathrm{n}, \mathrm{x}$ \\
\hline hire & fire, hare, hike, here & walk, eggy, huff, maid & h & $\mathrm{b}, \mathrm{d}, \mathrm{k}, \mathrm{f}$ & $\mathrm{g}, \mathrm{q}, \mathrm{v}, \mathrm{w}$ \\
\hline heed & heel, weed, herd, feed & olla, eddy, skim, aide & $\mathbf{r}$ & $f, t, v, n$ & $\mathrm{p}, \mathrm{y}, \mathrm{k}, \mathrm{d}$ \\
\hline hilt & hint, jilt, kilt, wilt & acne, apse, seer, anew & m & $\mathrm{n}, \mathrm{u}, \mathrm{w}, \mathrm{v}$ & $y, p, t, o$ \\
\hline host & hoot, hose, post, dost & skin, alto, chin, ably & s & $a, x, z, n$ & $\mathbf{b}, \mathbf{k}, \mathbf{q}, \mathbf{g}$ \\
\hline dope & hope, dose, dove, cope & pity, play, stub, glut & a & $\mathrm{s}, \mathrm{z}, \mathrm{x}, \mathrm{e}$ & $1, \mathrm{j}, \mathrm{i}, \mathrm{w}$ \\
\hline pink & pint, ping, punk, pine & cake, mute, oaks, arts & p & $g, q, y, j$ & $u, d, r, s$ \\
\hline land & lank, lard, laud, band & wily, site, mite, shin & $\mathbf{i}$ & $\mathrm{l}, \mathrm{f}, \mathrm{t}, \mathrm{h}$ & $\mathrm{w}, \mathrm{m}, \mathrm{u}, \mathrm{g}$ \\
\hline tape & tale, tame, gape, rape & spry, slag, spot, plod & o & $\mathrm{c}, \mathrm{e}, \mathrm{n}, \mathrm{a}$ & $\mathrm{d}, \mathrm{q}, \mathrm{l}, \mathrm{i}$ \\
\hline bold & bolt, cold, bond, hold & claw, plum, show, thug & $\mathrm{d}$ & $\mathrm{b}, \mathrm{h}, \mathrm{k}, \mathrm{t}$ & $z, v, y, j$ \\
\hline cork & cord, corn, fork, pork & pile, gigs, this, ills & $\mathbf{v}$ & $u, r, w, n$ & $\mathrm{~g}, \mathrm{l}, \mathrm{h}, \mathrm{f}$ \\
\hline play & clay, plan, pray, slay & sold, bale, hate, sell & $\mathbf{x}$ & $\mathrm{z}, \mathrm{a}, \mathrm{s}, \mathrm{v}$ & $\mathrm{l}, \mathrm{h}, \mathrm{p}, \mathrm{i}$ \\
\hline boot & boon, foot, hoot, boor & slim, spit, pigs, ugly & k & $h, b, d, t$ & $\mathrm{r}, \mathrm{s}, \mathrm{a}, \mathrm{e}$ \\
\hline mute & mate, mete, lute, mule & glad, they, plop, clod & b & $h, d, k, l$ & $z, q, w, r$ \\
\hline toil & foil, tail, coil, boil & aqua, eyes, pray, mire & $\mathbf{u}$ & $\mathrm{v}, \mathrm{n}, \mathrm{o}, \mathrm{c}$ & $\mathrm{l}, \mathrm{p}, \mathrm{g}, \mathrm{i}$ \\
\hline stub & snub, stun, stab, stud & trim, prig, pulp, balm & f & $\mathrm{t}, \mathrm{i}, \mathrm{l}, \mathrm{h}$ & $\mathrm{w}, \mathrm{q}, \mathrm{n}, \mathrm{o}$ \\
\hline slim & slit, slam, slum, slid & grey, tank, bunt, hurt & c & $o, e, a, s$ & $y, j, b, l$ \\
\hline coke & cake, toke, code, poke & girl, that, idol, glut & $\mathbf{y}$ & $\mathrm{j}, \mathrm{p}, \mathrm{q}, \mathrm{g}$ & $b, h, m, u$ \\
\hline
\end{tabular}

